\title{
Simulation and Fabrication of a Wilkinson 8-port Unequal Power Splitter
}

\author{
Mohammad Amir Ghasemi Shabankareh", Elnaz Arman
}

Department of Electrical Engineering, Shiraz Branch, Islamic Azad University, Iran

Copyright $\mathrm{C} 2019$ by authors, all rights reserved. Authors agree that this article remains permanently open access under the terms of the Creative Commons Attribution License 4.0 International License

\begin{abstract}
In this paper, a Wilkinson 8-port unequal power splitter with symmetric power division among corresponding ports is investigated. Simulation and fabrication results show desirable power transmission at central frequency of $9.68 \mathrm{GHz}$. This power splitter has transmission power of $-13.25 \mathrm{~dB}$ at corresponding ports 2 and $9,-11.4 \mathrm{~dB}$ at ports 3 and $8,-10.36 \mathrm{~dB}$ at ports 4 and 7 , $-9.7 \mathrm{~dB}$ at ports 5 and 6 . In addition, the proposed power splitter is suitable for feeding the array antenna due to its $-16 \mathrm{~dB}$ return loss and it minimizes return loss.
\end{abstract}

Keywords Simulation, Wilkinson, Power Splitter

\section{Introduction}

The Wilkinson power divider has been widely used in antennas and microwave power circuits, since its design is very simple, and thus, is easier to construct in comparison with the other compact microwave circuits [1-4]. Although this technology is not applicable for flat dividers, it is highly suitable for impedance matching in all frequency bands. Another reason that distinguishes these power divisors is due to the fact that isolation is one of the most important factors in the microwave circuits, where these dividers make it possible for all ports in microwave circuits. Furthermore, in many applications there is a need for microstrip power divider circuits with high power division rate. However, in unequal power dividers, the power division rate could increase the microstrip lines characteristic impedance. This process occurs in narrow microstrip lines, where we face many problems even to construct these circuits. The defected ground structure method has been proposed to construct microwave circuits, which could increase the circuit characteristic impedance [5-7]. However, since the isolation of the structure should be maintained, this method also has some restrictions, and thus, a double-sided parallel strip-line method is proposed that introduces a new type of Wilkinson power divider which maintains the maximum characteristic impedance
[8]. Implementing this method also involves some issues which imply the development of this method that has led to introduce another method which finally enhances the problems to some extent. This technique is proposed as "The Grooved Substrate", which is very useful in order to realize the high power division rate. However, the grooved substrate method has some difficulties in terms of construction compared to other common methods. In [10], a separate microstrip transmission line is placed among the circuits' outputs, which has led to the construction of a new class of unequal Wilkinson power dividers, where the transmission lines length is the only parameter that should be considered, and in addition, the output ports could be directly connected to the power divider without using the transformer resistance. However, employing this method decreases the bandwidth. Connecting a low characteristic impedance that is associated with transmission lines, along with two transmission lines, brings a new definition of power divider [11]. This method increases the microstrip circuit dimensions. In [12], an approach is presented to design Wilkinson power dividers, which increases the power division rate. In this method, a T-shaped microstrip structure with low characteristic impedance is placed in the circuit, which resolves the bandwidth-related problems to some extent. But, in designing microwave circuits, volume and size of design considering wavelength and frequency are variable. 3-port network known as T-junction network was first proposed by Cohen [2] in 1966. In this network, 2 match loads are connected to two output ports. This way, return loss at both ports is reduced. Similar studies have been conducted to improve return loss based on 3-port network [13][2]. In 60s, Mr. Wilkinson [1] proposed equal power splitter. This power splitter is transformed based on 3-port network theory which is one of the most effective references in studies. This power splitter plays the most important role in feeding array antennas. In this paper, 8-port unequal power splitter is analyzed and simulated at $\mathrm{X}$-banc. This power splitter is developed based on binary topology. First, a power splitter with three 3-ports power splitter stages where each stage divides $-3 \mathrm{~dB}$ power is assumed. Finally, this is performed by developing an equal 
power splitter preserving binary topology and changing width of microstrip lines and inserting a resistance to decouple ports. In order to simulate the equal power splitter, ADS and HFSS are used and the final unequal power splitter scheme is analyzed in HFSS. Wilkinson equal power splitter is designed using FR4 substrate with $0.5 \mathrm{~mm}$ thickness and $\varepsilon_{r}=3.38$, and unequal Wilkinson power splitter is simulated using rogers 4003 semiconductor layer with $0.5 \mathrm{~mm}$ thickness and $\varepsilon_{r}=3.55$.

\section{A Review on Wilkinson Power Splitter}

T-junction power splitters have two main disadvantages including:

1.Mismatch, 2. Coupling between ports

Since a 3-port network with loss can be fabricated such that all its ports are matched and output ports are decoupled, Wilkinson power splitter is introduced [1] which resolves all the introduced problems. Wilkinson power splitter has maximum decoupling and if all ports are matched, it is called lossless. In addition, T-power splitter lacks these advantages. However, resistive power splitter has best match. Best selection in this design is Wilkinson power splitter which converts all introduced disadvantages to its advantages. Fig. 1 shows Wilkinson power splitter.

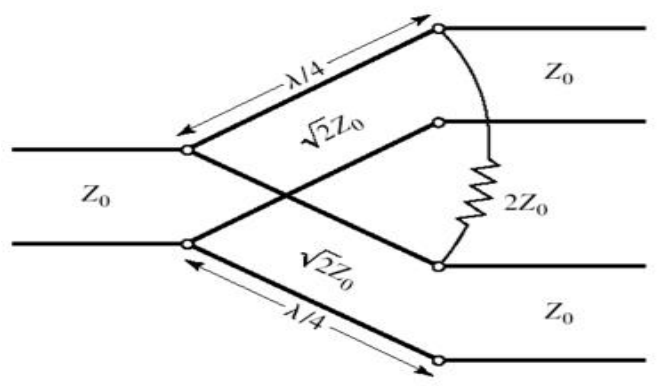

a

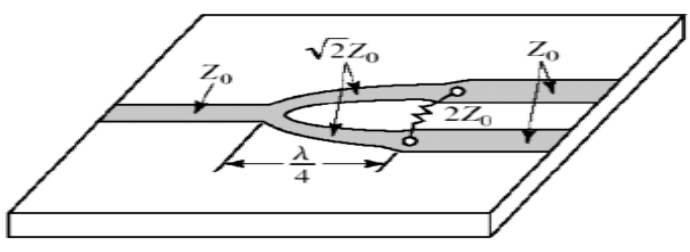

b

Figure 1. Wilkinson power splitter [3]. An equivalent circuit of the power transmission line splitter b micro-strip form of Wilkinson power Splitter

\subsection{Degree Chamber Bend}

This structure is used to compensate for the microstrip circuits discontinuities. Here, a 90-degree chamber [18] bend is used, which makes it easy for us to operate on band x. The efficiency of this structure is shown in the fig.2.

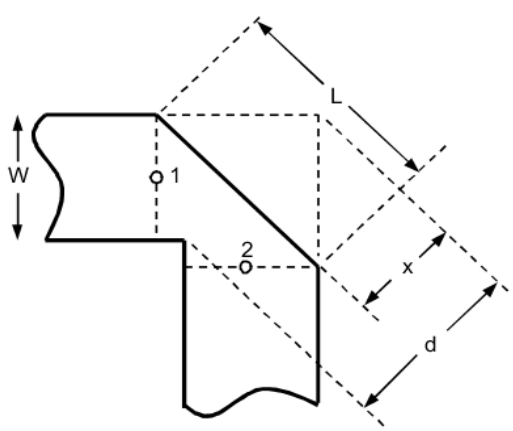

Figure 2. A 90-degree chamber bend[18]

The calculations are as follows:

$$
\begin{gathered}
l=w \times\left(\frac{m}{50}-1\right) \\
m=52+65\left[\exp \left(-1.35 \frac{w}{h}\right)\right. \\
m=\frac{x}{d} 100 \\
d-x=\sqrt{2} \times w \times(1-m)
\end{gathered}
$$

Where " $\mathrm{m}$ " in relation (2) is generally for all chamber bends, and in relation (3) is for 90 degree chamber bend. "h" is the semiconductor layer thickness in semiconductor circuits.

\section{Solving Scattering Parameters}

In order to obtain scattering parameters of Wilkinson power splitter, odd and even mode analysis is used which is obtained using symmetric circuit of this power splitter [3]. Equivalent circuit of odd and even mode analysis is shown in fig. 3 .
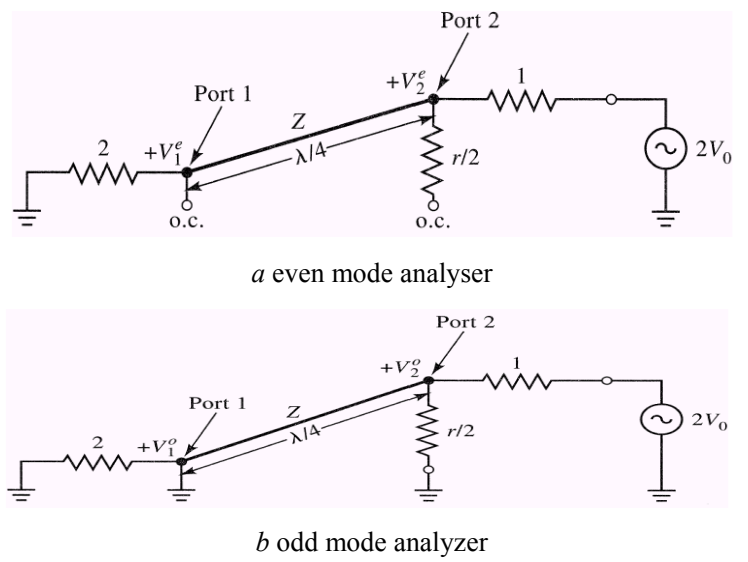

Figure. 3 Equivalent circuit of odd and even mode analysis [20]

$$
\begin{gathered}
Z=\frac{\sqrt{2}^{2}}{2}=1 \\
S_{11}=0
\end{gathered}
$$




$$
\begin{gathered}
S_{22}=S_{33}=0 \\
S_{12}=S_{21}=\frac{V_{1}^{e}+V_{1}^{0}}{V_{2}^{e}+V_{2}^{0}}=-j / \sqrt{2} \\
S_{13}=S_{31}=-j / \sqrt{2} \\
S=-\frac{1}{\sqrt{2}}\left[\begin{array}{lll}
0 & j & j \\
j & 0 & 0 \\
j & 0 & 0
\end{array}\right]
\end{gathered}
$$

Considering voltage in odd and even analysis, scattering parameters and input impedance [3] are obtained.

\section{Reviewing Wilkinson Unequal Power Splitter}

Wilkinson power splitter can be constructed as an unequal power splitter and its micro-strip line model is shown in fig.4. If power ratio between ports 2 and 3 is $K^{2}=\frac{P_{3}}{P_{2}}$, following equations are used [14], [15], [1]:

$$
\begin{gathered}
Z_{03}=Z_{0} \sqrt{\frac{1+K^{2}}{K^{3}}} \\
Z_{02}=K^{2} Z_{03}=Z_{0} \sqrt{K\left(1+K^{2}\right)} \\
R=Z_{0}\left(k+\frac{1}{K}\right)
\end{gathered}
$$

It should be noted for $\mathrm{K}=1$, simple power splitter is obtained [14], [15], [1]; in addition, it should be considered that output lines are matched with impedances $R_{2}=Z_{0} K$ and $R_{3}=Z_{0} / K$, in order to transfer these output impedances, matching transformers can be employed.

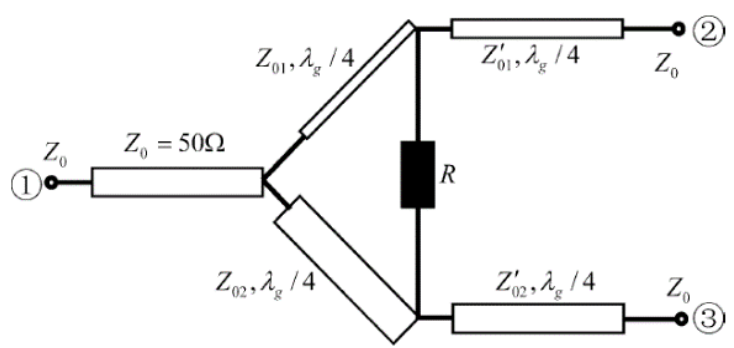

Figure 4. Simple topology of 2-port unequal power Splitter Design Method [19]

Designing 8-port unequal power splitter includes several stages. First, 8-port unequal power splitter with three 3-port network stages which are equal power splitters is implemented. Each port passes $-3 \mathrm{~dB}$ power. Finally, 8-port unequal Wilkinson power splitter is developed by obtaining 8-port Wilkinson power splitter in X-band. According to software calculations, there are two factors for developing unequal power splitter including micro-strip line width and isolation resistance between lines.

\section{8-port Equal Wilkinson Power Splitter}

In order to implement equal power splitter in $\mathrm{ADS}$, central frequency $9.65 \mathrm{GHz}$ with FR4 substrate with $0.5 \mathrm{~mm}$ thickness and $\varepsilon_{r}=3.38$ is used. Fig.5 shows schematic of 2-port equal Wilkinson power Splitter.

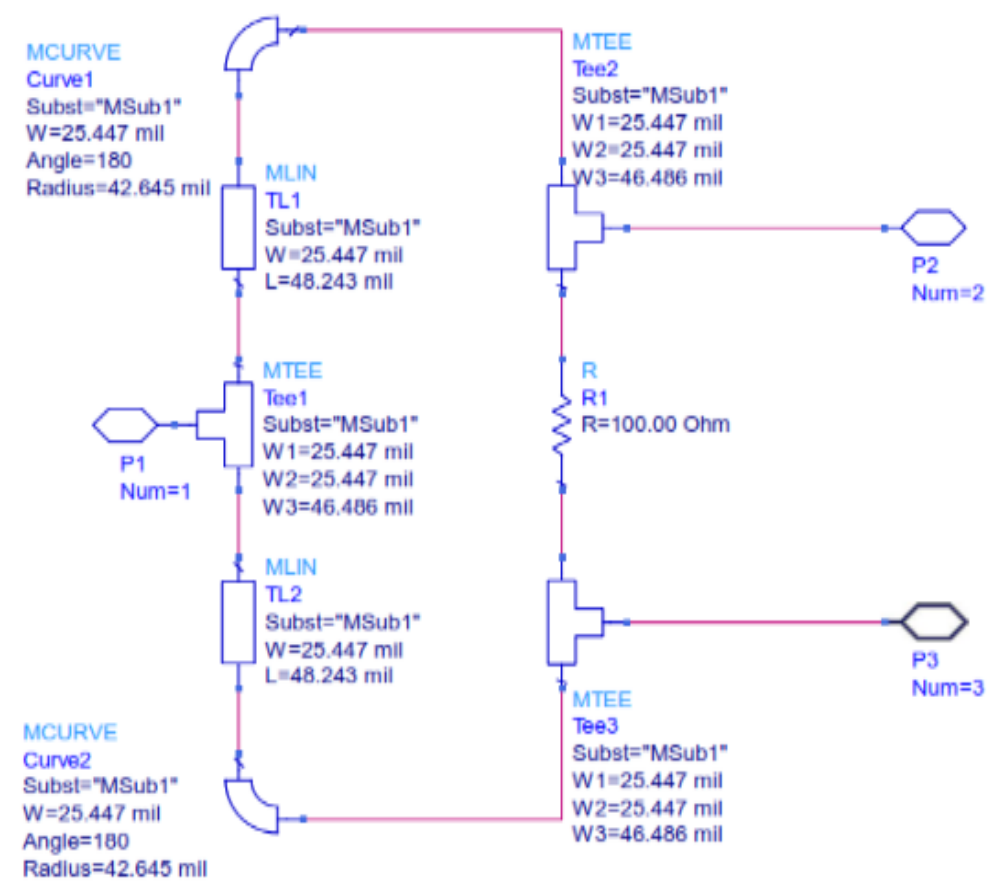

Figure 5. Simple topology of 2-port equal power splitter design method in ADS software 
Results of 2-port Wilkinson power splitter in ADS are shown in Fig.6. After extending 2-port equal power splitter to 8-port power splitter, its schematic in HFSS is as follows.

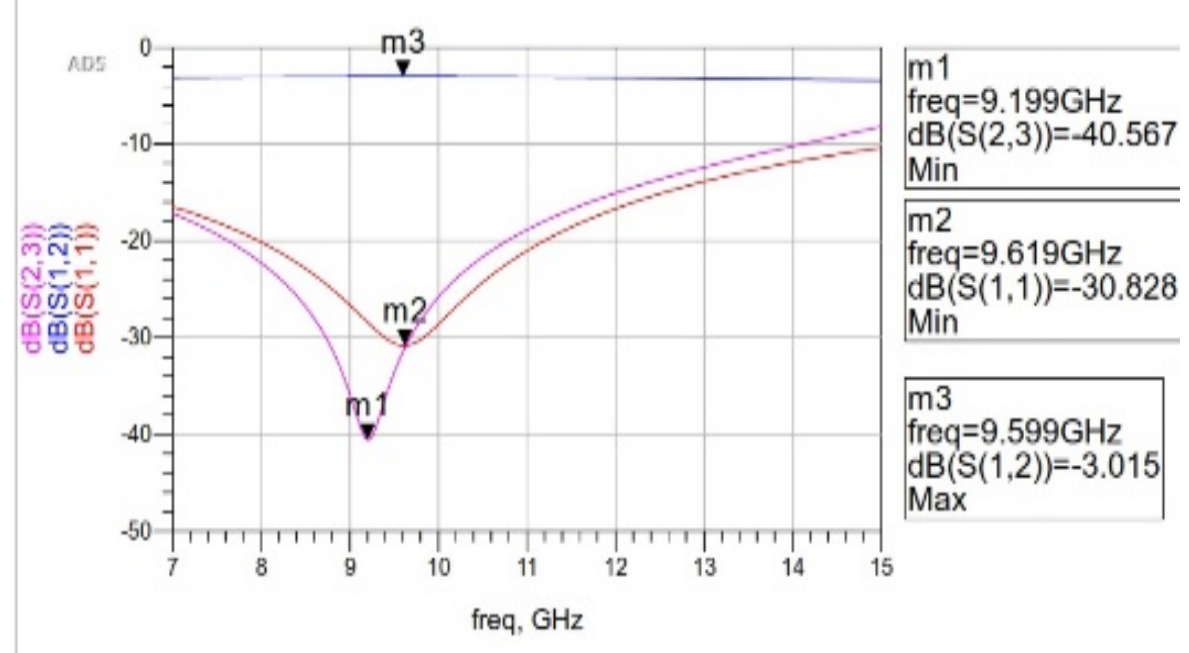

Figure 6. Results of simulating scattering matrix (S11, S12) in ADS

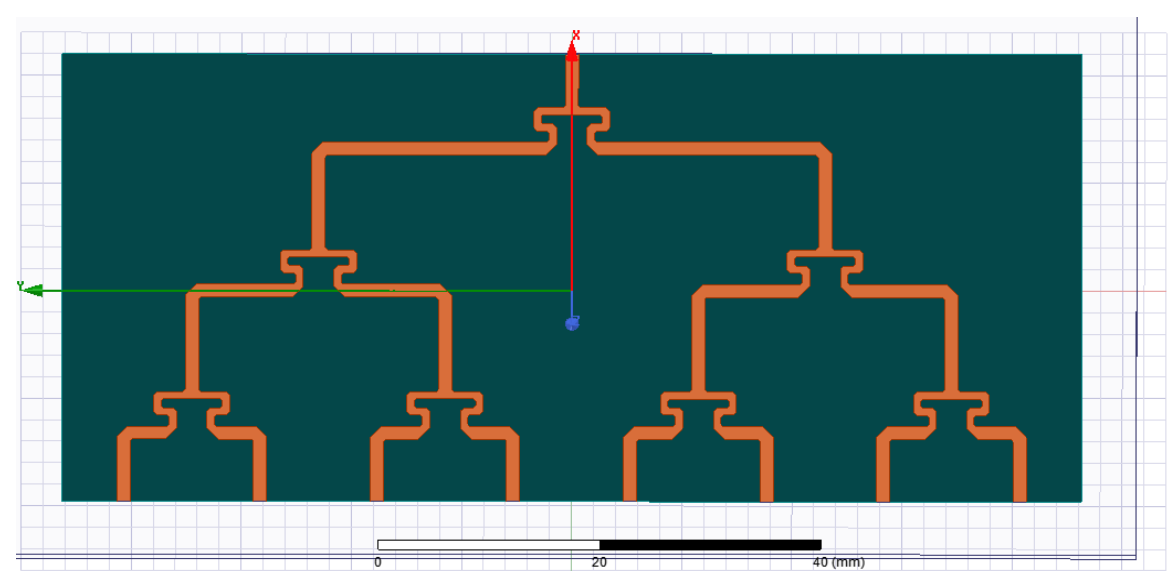

Figure 7. Simulated of 8-port equal Wilkinson power splitter in HFSS [16].

Fig.7 shows designed of 8-port equal Wilkinson power splitter simulated in HFSS software at X-band.

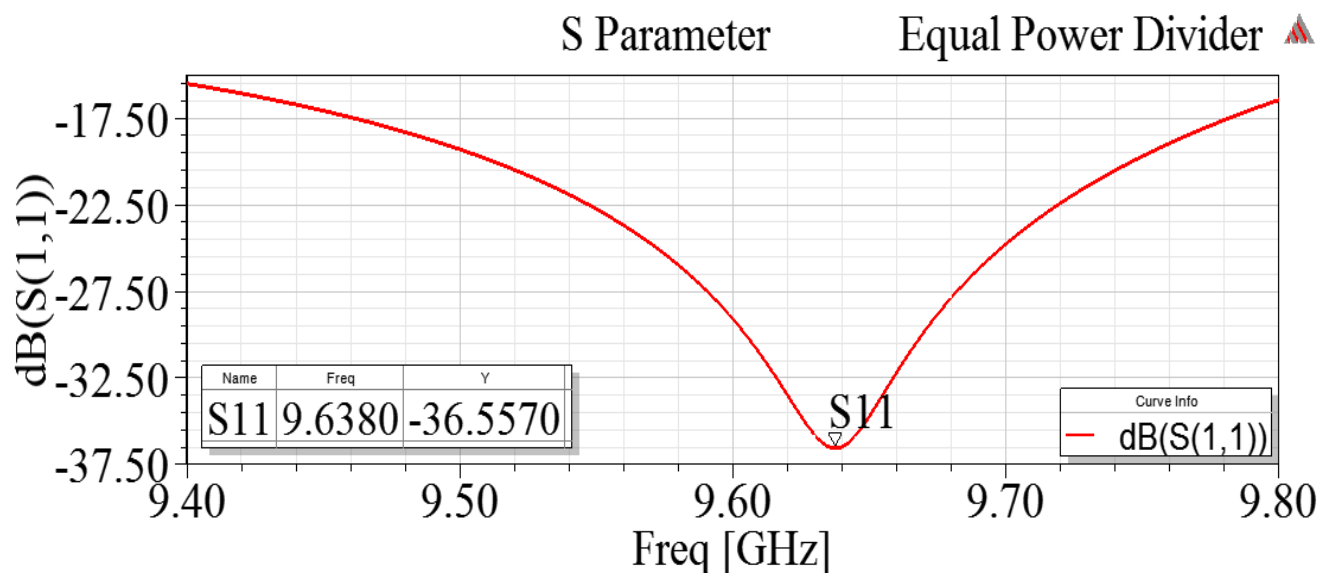

Figure 8. Return loss $\mathrm{S} 11$ at $9.638 \mathrm{GHz}[16]$.

Fig. 8 shows return loss S11 and insertion at $9.638 \mathrm{GHz}$ by HFSS software.

After implementing 8-port equal Wilkinson power Splitter in HFSS, simulation results including insertion loss, return loss are as follows. 


\section{Designing 8-port Unequal Wilkinson Power Splitter}

Unequal power divider has simulated in the HFSS software after designing in ADS. The simulation results have shown in Fig. 10 and Table.1 After obtaining important parameters such as insertion loss which have been reliable, this power divider transfers to the fabrication phase. Finally, after measuring the results of the fabrication, it has shown in the Fig. 11 and Table.2. All of these measurements are achieved in the X-band. Final schematic of unequal Wilkinson power splitter in HFSS is as follows:

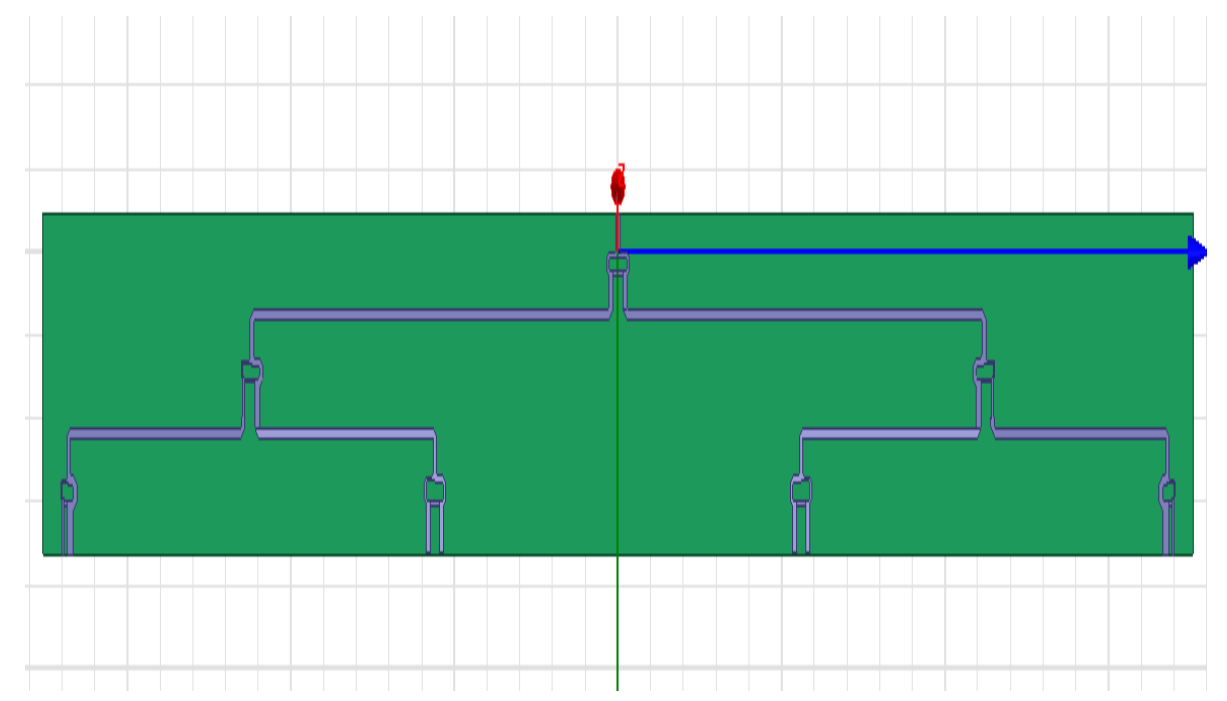

Figure 9. Designed 8-port Unequal power splitter in HFSS software [16].

Fig. 9 shows 8-port unequal Wilkinson power splitter simulated in HFSS at X-band and simulation results are as follows.

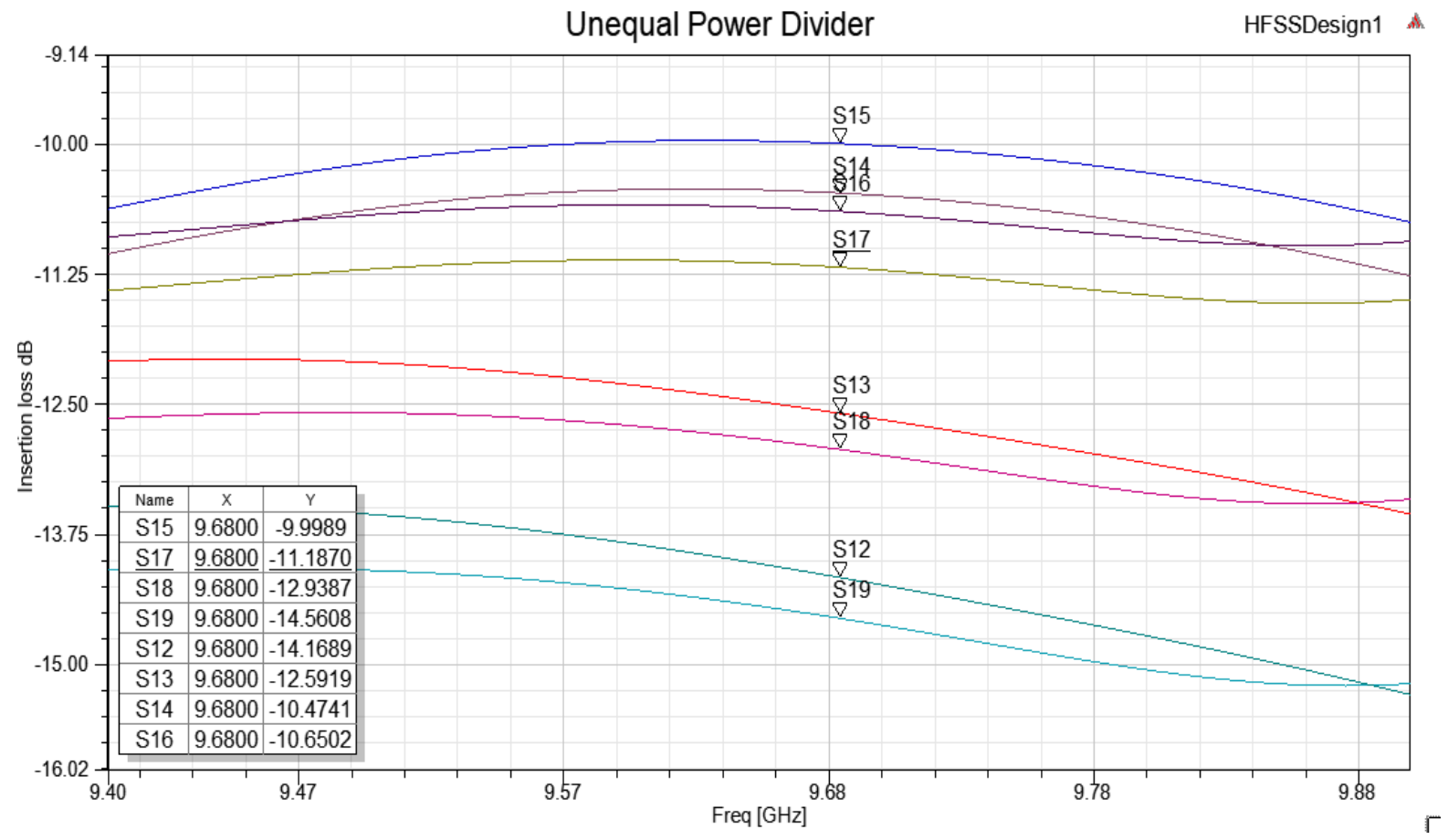

Figure 10. Insertion loss from port 1 to other ports given in Table (1)[16].

Fig.10 shows insertion loss from port 1 to all port at $9.68 \mathrm{GHz}$ by HFSS software. 
Table 1. Insertion loss from port 1 to other ports at $9.68 \mathrm{GHz}[16]$.

\begin{tabular}{|c|c|}
\hline Scattering parameters & Insertion loss at each port \\
\hline S12 & $-14.16 \mathrm{~dB}$ \\
\hline S13 & $-12.59 \mathrm{~dB}$ \\
\hline S14 & $-10.47 \mathrm{~dB}$ \\
\hline S15 & $-9.99 \mathrm{~dB}$ \\
\hline S16 & $-10.65 \mathrm{~dB}$ \\
\hline S17 & $-11.18 \mathrm{~dB}$ \\
\hline S18 & $-12.93 \mathrm{~dB}$ \\
\hline S19 & $-14.56 \mathrm{~dB}$ \\
\hline
\end{tabular}

The Measured Data of Unequal Power Divider

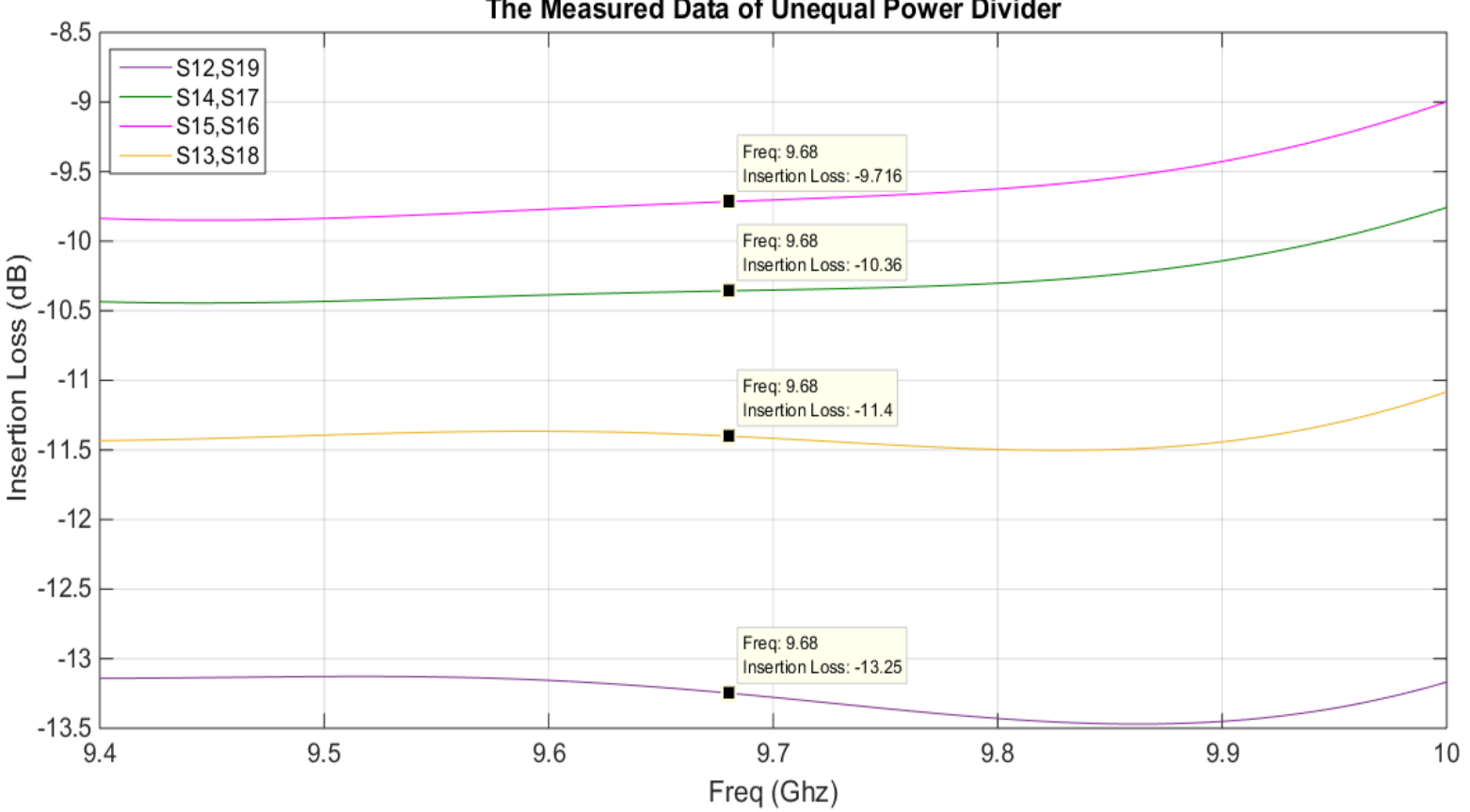

Figure 11. Insertion loss from port 1 to other after fabrication

Fig. 11 shows insertion loss from port 1 to all port at $9.68 \mathrm{GHz}$ after fabrication.

Table 2. Insertion loss from port 1 to other ports at $9.68 \mathrm{GHz}$ after fabrication.

\begin{tabular}{|c|c|}
\hline Scattering Parameters & insertion Loss at each port \\
\hline S12 & $-13.25 \mathrm{~dB}$ \\
\hline S13 & $-11.4 \mathrm{~dB}$ \\
\hline $\mathrm{S} 14$ & $-10.36 \mathrm{~dB}$ \\
\hline $\mathrm{S} 15$ & $-9.7 \mathrm{~dB}$ \\
\hline $\mathrm{S} 16$ & $-9.7 \mathrm{~dB}$ \\
\hline $\mathrm{S} 17$ & $-10.36 \mathrm{~dB}$ \\
\hline $\mathrm{S} 18$ & $-11.4 \mathrm{~dB}$ \\
\hline $\mathrm{S} 19$ & $-13.25 \mathrm{~dB}$ \\
\hline
\end{tabular}

Comparison of fabrication and simulation results have been shown in Table.3. 
Table 3. Insertion loss of fabrication and simulation from port 1 to other ports at $9.68 \mathrm{GHz}$

\begin{tabular}{|c|c|c|c|}
\hline Scattering parameters & Fabrication result & Simulation result & Difference of two parameters \\
\hline S12 & $-13.25 \mathrm{~dB}$ & $-14.16 \mathrm{~dB}$ & $0.91 \mathrm{~dB}$ \\
\hline $\mathrm{S} 13$ & $-11.4 \mathrm{~dB}$ & $12.59 \mathrm{~dB}$ & $1.19 \mathrm{~dB}$ \\
\hline $\mathrm{S} 14$ & $-10.36 \mathrm{~dB}$ & $-10.47 \mathrm{~dB}$ & $0.11 \mathrm{~dB}$ \\
\hline $\mathrm{S} 15$ & $-9.7 \mathrm{~dB}$ & $-9.99 \mathrm{~dB}$ & $0.29 \mathrm{~dB}$ \\
\hline $\mathrm{S} 16$ & $-9.7 \mathrm{~dB}$ & $-10.65 \mathrm{~dB}$ & $0.95 \mathrm{~dB}$ \\
\hline $\mathrm{S} 17$ & $-10.36 \mathrm{~dB}$ & $-11.18 \mathrm{~dB}$ & $0.82 \mathrm{~dB}$ \\
\hline $\mathrm{S} 18$ & $-11.4 \mathrm{~dB}$ & $-12.93 \mathrm{~dB}$ & $1.53 \mathrm{~dB}$ \\
\hline $\mathrm{S} 19$ & $-13.25 \mathrm{~dB}$ & $-14.56 \mathrm{~dB}$ & $1.31 \mathrm{~dB}$ \\
\hline
\end{tabular}

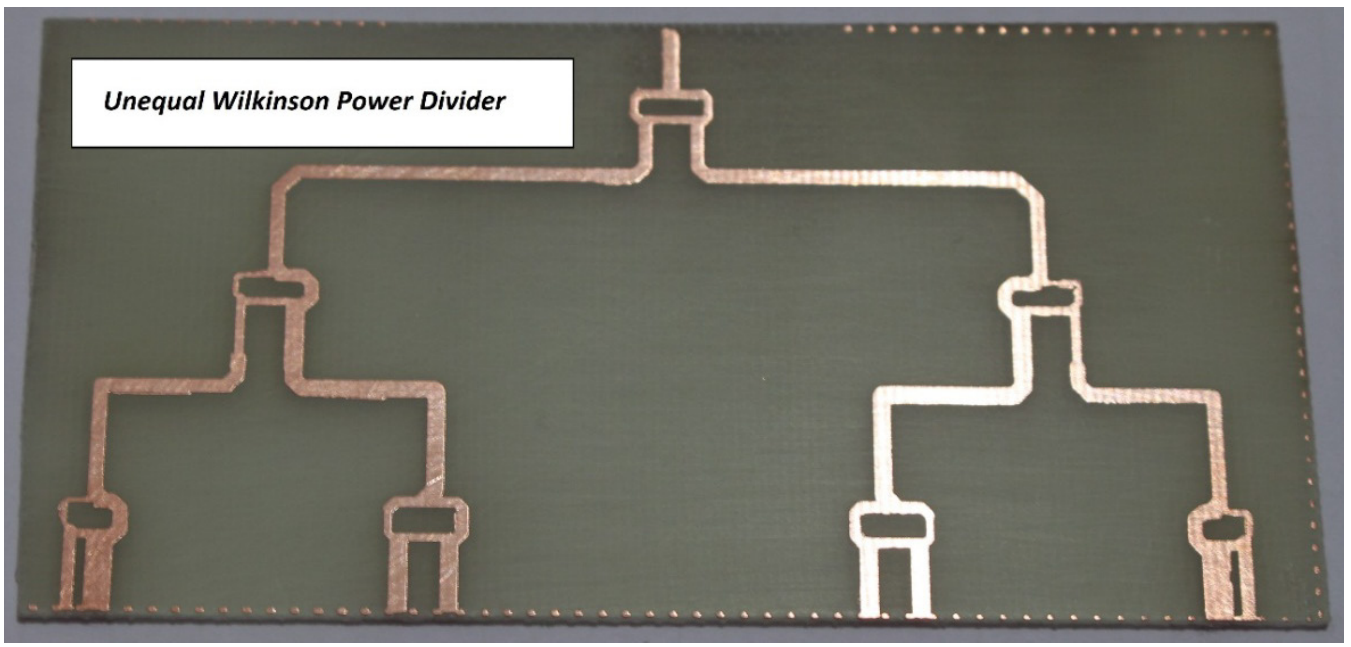

Figure 12. Photograph of the fabricated structure

Fig. 12 shows Photograph of the fabricated Unequal Wilkinson power divider.

\section{Conclusions}

Design and fabrication of equal power splitters is easy which has been commercialized; each architecture requires optimal design depending on volume circuit for microwave devices and operating frequency which can result in maximum efficiency. Thus, this paper tries to present a new binary architecture based on equal power splitter which not only results in suitable impedance matching but also an accurate frequency response is obtained at central frequency of $9.6 \mathrm{GHz}$; finally, using 8-port equal power splitter, binary 8-port unequal power splitter is realized considering structure which plays an important role in success and achieving suitable response.

\section{REFERENCES}

[1] Wilkinson, E., “An N-way hybrid power divider," IRE Trans. On Microw. Theory Tech., Vol. 8, No. 1, 116\{118, Jan. 1960 .
[2] Cohn, S. B., "A class of broadband three port TEM-mode hybrids," IEEE Trans. on Microw. Theory and Tech., Vol. 16, Pozar, D. M., Microwave Engineering, 2nd Edition, Wiley, New York, 1998

[3] Pozar, D. M., Microwave Engineering, 2nd Edition, Wiley, New York, 1998.

[4] Collin, R. E., Foundations for Microwave Engineering, 2nd Edition, McGraw Hill, 1992

[5] Lim, J.-S., S.-W. Lee, C.-S. Kim, J.-S. Park, D. Ahn, S. Nam, "A 4: 1 unequal Wilkinson power divider," IEEE Microw. Wireless Compon. Lett., Vol. 11, No. 3, 124\{126, Mar. 2001.

[6] Lim, J.-S., G.-Y. Lee, Y.-C. Jeong, D. Ahn, and K.-S. Choi, 'A $1: 6$ unequal Wilkinson power divider," 36th European Microwave Conference Proceedings, 200\{203, Manchester, Sep. 2006 Progress In Electromagnetics Research C, Vol. 36, 201327

[7] Zhang, Z., Y.-C. Jiao, S. Tu, S.-M. Ning, and S.-F. Cao, “A miniaturized broadband 4: 1 unequal Wilkinson power divider," Journal of Electromagnetic Waves and Applications, Vol. 24, No. 4, 505\{511, 2010.

[8] Chen, J.-X. and Q. Xue, "Novel 5: 1 unequal Wilkinson power divider using ofset double-sided parallel-strip lines," IEEE Microw. Wireless Compon. Lett., Vol. 17, No. 3, $175\{177$, Mar. 2007.

[9] Moradian, M. and H. Oraizi, "Application of grooved 
substratesfor design of unequal Wilkinson power dividers," Electronics Letters, Vol. 44, No. 1, Jun. 2008.

[10] Cheng, K. K. M. and P. W. Li, "A novel power divider design with unequal power dividing ratio and simple layout," IEEE Trans. On Microw. Theory and Tech., Vol. 57, No. 6, 1589\{1594, Jun. 2009.

[11] Wu, Y., Y. Liu, S. Li, and C. Yu, "Extremely unequal Wilkinson power divider with dual transmission lines," Electronics Letters, Vol. 46, No. 1, 90\{91, 2010.

[12] Yang, T., J. Chen, and Q. Xue, "Novel approach to the design of unequal power divider with high dividing ratio," Microwave and Optical Technology Letters, Vol. 51, No. 5, $1240\{1243$, May 2009.

[13] M. E. Goldfarb, "A recombinant, in-phase power divider," IEEE Trans. Microwave Theory Tech., vol. 39, no. 8, pp. 1438-1440, Aug. 1991

[14] K. Chang, Encyclopedia of RF and Microwave Engineering. New Jersey: John Wiley \& Sons Inc, 2005

[15] A. Grebennikov, RF and Microwave Transmitter Design. New Jersey: John Wiley \& Sons Inc, 2011.

[16] M. A. G. Shabnkare, "Design and Simulation of the Unequal 8-Way Binary Power Divider," M.S, Electrical Department, Shiraz Branch, Islamic Azad University, 2017. Unpublished.

[17] R. H. J. M. Kirschning, and N. H. L. Koster, "Measurement and Computer-Aided Modeling of Microstrip Discontinuities by an Improved Resonator Method," EEE MTT-S International Microwave Symposium Digest, 1983.

[18] R.J.P. Douville and D.S. James, Experimental Study of Symmetric Microstrip Bends and Their Compensation, IEEE Transactions on Microwave Theory and Techniques, Vol. MTT-26, March 1978, pp. 175-181.

[19] B. Li, X. Wu and W. Wu, "A 10:1 Unequal Wilkinson Power Divider Using Coupled Lines with Two Shorts," in IEEE Microwave and Wireless Components Letters, vol. 19, no. 12, pp. 789-791, Dec. 2009.

[20] D. D. Harty "Novel design of a wideband ribcage-diploe array and its feeding network "MS, Worcester Polytechnic Institute, Dec. 2010 